\section{A nova lei portuária brasileira}

Wilen Manteli

Advogado

SUMÁRIO:

Considerações iniciais; - Dos terminais privativos; - As relações de trabalho.

\section{Abstract}

The new port brazilian law

In 1993, the Brazilian National Congress approved the law $n .8 .630$, that changed the port new legal system.

The new port law is known as the modernization of the ports, because it has extinguished the two monopolies: state and unions dockworkers.

In consequence of this the ports services could be all privatised and the work conditions would be openly and freely dealt among employers and workers.

Therefore, the brazilian ports will have the free competition, having as great beneficiary the customers of the ports.

\section{Considerações iniciais}

Finalmente, com atraso de décadas, o governo brasileiro resolveu enfrentar a velha e preocupante questão portuária.

Os portos brasileiros, de um lado, dominados pela burocracia estatal e, de outro, pelo monopólio dos sindicatos dos trabalhadores da orla marítima, se constituíam no principal entrave do desenvolvimento econômico e social do País.

$O$ que havia era verdadeiro cipoal legislativo regulando a atividade portuária: leis, decreto-leis, decretos, portarias, resolu- ções e outros atos normativos pautavam pelo intervencionismo estatal e pela concessão de benesses às várias categorias de trabalhadores sindicalizados. A raiz dessa parafernália legislativa vinha dos idos de 1930 e tinha como fonte inspiradora a fascita legislação italiana.

Após tumultuada tramitação no Congresso Nacional, palco do embate entre os que buscavam modernizar o sistema portuário nacional e os estatizantes e corporativistas, defensores do statu quo, interessados em ampliar o intervencionismo e os privilégios, foi, finalmente, promulgada a Lei $\mathrm{n}^{\circ} 8.630$, de 1993. Esses últimos - os privilegiados com a situação - contaram com forte apoio dos legisladores populistas, por ignorarem ser "a lei instrumento de realização da justiça e não o meio para outorga de benesses", no dizer de Frédéric Bastiat em "A Lei", publicada em 1850.

Forçoso é reconhecer que não é a lei esperada e ideal para impulsionar a atividade econômica, mas, mesmo assim, em razão do que havia, pode-se considerar verdadeiro avanço, pelo menos para se iniciar uma mudança modernizante nesse importante segmento da atividade econômica.

A referida lei, é oportuno dizer, está em plena sintonia com a Constituição Federal, que, em seu artigo $21, \mathrm{XII}$, diz competir à União a exploração dos portos marítimos fluviais e lacustres, diretamente ou median- te delegação a terceiros. A Carta Magna também confere competência privativa à União para legislar sobre o regime dos portos.

\section{Aspectos estruturais}

Conforme consta em sua ementa, a lei cuida do novo regime jurídico da exploração portuária. Trata, de início, das duas espécies de porto. A primeira, "porto organizado", que melhor seria denominá-lo de público, evitando assim maiores confusões. $\hat{E}$ aquele de uso público, explorado diretamente pela União ou por terceiros, mediante concessão, sujeita sempre à licitação. A segunda espécie refere-se às "instalações portuária de uso privativo", evidentemente que, também, organizado, mais conhecida como terminal privativo. É aquele explorado por pessoa jurídica de direito público ou privado, destinado à movimentação de cargas pró prias e de terceiros.

A administração do "porto organizado" compete: I) - ao "Conselho de Autoridade Portuária" (CAP) espécie do "port authority" dos americanos, órgão colegiado responsável pela formulação da política de exploração do porto, composto por repre sentantes do poder público, dos usuários do porto, dos operadores portuários e dos trabalhadores; e II) - à "Administração do Porto Organizado", com funções executivas, cabendo-lhe cumprir e fazer cumprir as disposições legais e as deliberadas pelo CAP.

A atuação do "porto organizado" dá-se dentro do espaço que a lei definiu como "área do porto organizado". Definição essa que se prestará apenas para gerar confusões e conflitos na aplicação da lei, porque, só para citar um exemplo, há tratamento diferenciado para os terminais localizados dentro ou fora da referida área. Tal definição, desnecessária até, apenas revela ranço intervencionista do nosso legislador.

\section{Dos terminais privativos}

Quanto aos terminais privativos, embora a sua história remonte ao tempo do Império, quando o governo concedia aos particulares, diga-se sem as dificuldades burocráticas de hoje, o direito de construção e exploração de instalações portuárias, foram, nos últimos 50 anos, tratados de forma nebulosa e casuística.

O professor Celso Antonio Bandeira de Mello, renomado mestre em Direito Administrativo, ao examinar a questão dos termi nais privativos, informa que aquela legislação era por demais fluída e, por isso mesmo, prevalecia mais os interesses próprios ou ate escusos do que os interesses nacionais na execução da política desse importante segmento da atividade portuária.

$\mathrm{Na}$ nova lei essas questões ficaram melhor definidas, embora estejam os terminais particulares submetidos ao cumprimento de uma gama infindável de exigências. Estabeleceu o legislador duas modalidades de terminais: o de uso público, aberto a todos, destinado a movimentar cargas para o público, geralmente especializado em um ou mais tipo; e o de uso privativo, modalidade subdividida em terminal de uso exclusivo, para movimentação de carga própria da empresa detentora das instalações, e de uso misto, no qual poderão ser movimentadas mercadorias próprias e de terceiros, como forma de utilizar-se a eventual capacidade ociosa de um determinado terminal, aliás, antiga reivindicação do setor empresarial.

Sem dúvida - e a despeito da excessiva normatização a que estão submetidos - os terminais privativos, em qualquer de suas modalidades se constituem no mais importante avanço da lei, sendo a verdadeira resposta ao clamor pela privatização dos serviços portuários.

Diga-se que o objetivo central da Lei $n^{\circ}$ 8.630 foi a busca da desregulamentação, mo- 
dernização desse estratégico setor, ou seja, o legislador brasileiro acompanhou, ainda que com atraso, a tendência mundial que pauta pela privatização de diversos serviços públicos, como forma e modo de se buscar maior eficiência e menores custos, ou como dizem "fazer mais por menos".

\section{As relações de trabalho}

Outro avanço contemplado pela Lei $\mathrm{n}^{\circ}$ 8.630 , é a nova disciplina às relações capital/ trabalho. Embora ela não tenha regulado direitos e obrigações entre trabalhadores e seus tomadores de serviços, a lei eliminou o abusivo e danoso monopólio detido pelos vários sindicatos da orla marítima, impostos e aceitos por conveniência e omissão tanto das autoridades como dos próprios embarcadores. A lei retirou dos sindicatos a condição de fornecerem o trabalho da mãode-obra avulsa, fator de elevados custos na movimentação de cargas e de abusos generalizados, a impedir o avanço tecnológico.

A partir da nova lei, a mão-de-obra avulsa não será mais imposta pelos sindicatos. $\mathrm{O}$ órgão gestor de mão-de-obra passou a ser responsável pelo registro, treinamento e remuneração do trabalhador portuário, nos moldes do que existe nos principais portos internacionais. Evidentemente que o citado órgão terá que cumprir as condições constantes dos acordos negociados entre empresários e trabalhadores. E nisso reside importante mudança introduzida pela lei, substituindo velho procedimentos, remetendo trabalhadores e empresários à negociação coletiva, principalmente a nível regional. Será, portanto, na mesa de negociação, que empresários trabalhadores estabelecerão as con- dições de trabalho, a remuneração, a definição das funções, a composição dos ternos na busca, assim, da permanente melhoria dos serviços portuários e da produtividade. Com isso, deixando de ser fornecedores de mãode-obra - atividade incompatível para a entidade classista!

Importante ressaltar que o órgão gestor de mão-de-obra (OGMO) terá um Conselho Supervisor composto por trabalhadores e empresários, bem como uma Comissão Paritária com a finalidade de solucionar litígios nas relações capital-trabalho.

Atento às repercussões sociais decorrentes do novo regime de exploração portuária notadamente pela introdução de modernos sistemas de carga e descarga, o legislador estabeleceu, para atenuar o período de transição, o sistema de compensação pecuniária para os trabalhadores não aproveitados, nas condições recomendadas pela Organização Internacional do Trabalho - (OIT)

Digno de registro, portanto, é o fato da nova lei ter revogado todo aquele emaranhado conjunto de atos normativos, passando a vigir novo ordenamento jurídico para o sistema portuário, que, se aplicado e cumprido devidamente, dará não as melhores, mas aquelas condições mínimas para que o país possa se desenvolver social e economicamente num ritmo mais adequado às suas gigantescas necessidades sociais e econômicas.

\section{Bibliografia}

Catharino, José Martins. O Novo Sistema Portuário Brasileiro. Ed. Destaque, 1994

Oliveira, Carlos Tavares de. Modernização dos Portos. Ed. Aduaneiras, 1994.

Silva, Francisco Carlos de Morais. Direito Portuário. Ed. Del Rey, 1994.

\section{nulidade da lei inconstitucional e seus efeitos:}

\section{ideração sobre a decisão do STF proferida no RE n⿳ 122.202}

\section{nar Ferreira Mendes}

curador da República, Professor da Universidade de Brasília, Mestre em eito pela Universidade de Brasília, Doutor em Direito pela versidade de Münster - RFA.

LÁRIO

trodução; 2. A nulidade da lei inconstitucional; 3. A nulidade ipso jure e ex tunc; 4. A nulidade da lei e os atos lares praticados com base na lei inconstitucional; 5. Conclusão; Bibliografia.

\section{Introdução}

Em acórdão recém-publicado, o Supremo bunal Federal vem de afirmar que a retrição de servidor público declarada onstitucional não é de ser devolvida no peto da validade inquestionada da lei, tal como ê na ementa do acórdão:

"Recurso Extraordinário. Efeitos da Declarade Inconstitucionalidade em tese pelo SupreTribunal Federal. Alegação de Direito Adrido. Acórdão que prestigiou lei estadual à reia da declaração de inconstitucionalidade desiltima pelo Supremo. Subsistência do pagamen 'e gratificação mesmo após a decisão erga omnes Corte. Jurisprudência do STF no sentido de a retribuição declarada inconstitucional não !e ser devolvida no periodo de validade uestionada da lei de origem - mas tampouco ra após a declaração de inconstitucionalidade. surso extraordinário provido em parte"1.

Cuidava-se de recurso extraordinário intersto pelo Estado de Minas Gerais contra deão do Tribunal de Justiça daquele Estado e deferiu mandado de segurança para deternar a continuidade de pagamento de vantans consagradas em lei já declarada onstitucional pelo Supremo Tribunal.
Anteriormente já havia o Supremo Tribunal concluído que "a irredutibilidade dos vencimentos dos magistrados garante, sobretudo, o di reito que já nasceu e que não pode ser suprimido sem que sejam diminuidas as prerrogativas que suportam o seu cargo". Por essa razão, afirmouse, tal garantia haveria de superar o próprio efeito ex tunc da declaração de inconstitucionalidade da norma ${ }^{2}$.

A decisão mais recente, também relativa à remuneração de magistrados, retrata entendimento no sentido de que "retribuição declarada inconstitucional não é de ser devolvida no período de validade inquestionada da lei de origem - mas tamponco paga após a declaração de inconstitucionalidade ${ }^{\Perp 3}$.

A orientação esposada pelo Supremo Tribunal nos casos referidos merece uma análise mais atenta.

Contemple-se, inicialmente, a chamada nulidade da lei inconstitucional.

\section{A nulidade da lei inconstitucional}

O dogma da nulidade da lei inconstitucional pertence à tradição do direito brasileiro. A teoria da nulidade tem sido sustentada por praticamente todos os nossos importantes 